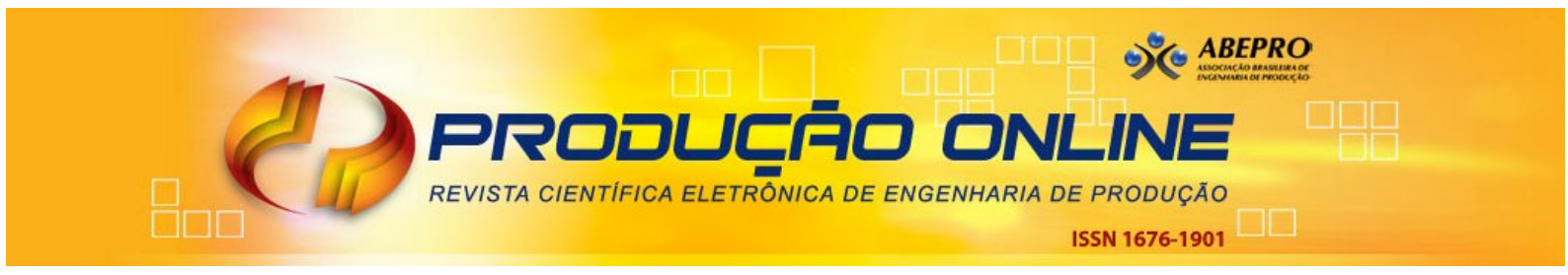

\title{
GESTÃO DE PROCESSOS NA CADEIA DE SUPRIMENTOS: UM ESTUDO DE CASO NUMA ORGANIZAÇÃO DO SETOR TÊXTIL DO AGRESTE DE PERNAMBUCO
}

\section{PROCESS MANAGEMENT IN SUPPLY CHAINS: A CASE STUDY IN A COMPANY OF TEXTILE INDUSTRY OF THE AGRESTE OF PERNAMBUCO}

\author{
Cícero Marcolino Pessoa de Sousa * E-mail: ciceromarcolino@hotmail.com \\ Lúcio Camara e Silva* E-mail: luciocsilva@gmail.com \\ *Universidade Federal de Pernambuco, Centro Acadêmico do Agreste (UFPE/CAA), Caruaru, PE
}

\begin{abstract}
Resumo: A cadeia de suprimentos (CS) integra o gerenciamento dos processos atribuídos à empresa foco, conectando-se com seus clientes, com seus fornecedores e consigo mesma. Esta gestão é dinâmica e reúne os processos de negócio que envolvem, desde o usuário final, até os fornecedores primários, provedores de produtos, serviços e informações que agregam valor aos clientes e stakeholders. Dada a importância da integração desses processos na CS, este trabalho tem como objetivo elaborar um diagnóstico, avaliar e propor melhorias com relação a gestão de processos ao longo da Gestão da Cadeia de Suprimentos (GCS), com base no modelo de Lambert et al. (1998) e através de uma análise SWOT. Esta pesquisa fez uso de uma abordagem qualitativa ajustada como exploratória a um estudo de caso realizado numa empresa do setor têxtil do Agreste de Pernambuco, sendo conduzido através de entrevistas presenciais e com base na aplicação de um questionário. Os resultados da pesquisa mostram que há ausência de práticas de modelos de gestão de processos, fator comprometedor à sua eficiência no GCS, como também a necessidade em formalizar os processos-chave no canal de suprimentos.
\end{abstract}

Palavras-chave: Gestão de processos. Cadeia de Suprimentos. SWOT. Setor Têxtil.

Abstract: The supply chain (SC) integrates the process management of the target enterprise, providing a connection with their clients, suppliers and within itself. This type of management is dynamic and it covers the business processes that involve since the final consumer to the primary suppliers which provide products, services and information that generate value to the consumers and stakeholders. Given the importance of the integration of these processes on a SC, this paper's objective is to elaborate a diagnosis to evaluate, and propose improvements relating to processes Management throughout the Supply Chain Management (SCM) based on the model by Lambert et al. (1998) as well as through a SWOT analysis. The present research has utilized a qualitative approach, adjusted to exploratory adapted to a case study applied on a company of the textile industry located on the wasteland region of Pernambuco state, and was conducted through personal interviews by the means of an elaborate questionnaire. The results show that there is a lack of process management models, which is a compromising factor to the efficiency of the processes involved on the SCM, as well as also show the need of formalization of the key-processes on the supply line.

Keywords: Process Management. Supply Chain Management. SWOT. Textile Industry.

\section{INTRODUÇÃo}

De acordo com GALDAMÉZ et al. (2009), um Arranjo Produtivo Local (APL) equivale a um sistema que pode promover a cooperação empresarial, a inovação 
contínua e o desenvolvimento sustentável de Pequenas e Médias Empresas (PMEs) localizadas numa região. Nesse sentido, as cidades de Caruaru, Toritama e Santa Cruz do Capibaribe, localizadas no Agreste de Pernambuco, formam um conceituado Polo de Confecções, caracterizando um APL com foco têxtil.

Porém, conforme Puga (2004) destaca, um APL integra um expressivo quantitativo de PMEs, o que predispõe instigar a disputa entre as organizações, aumentando as necessidades das mesmas em se manterem em posições de destaque. Com base nisso, vem a necessidade dessas empresas em utilizar alternativas diferenciadas que permitam competir com as demais. Dentre essas alternativas, tenta-se tornar mais eficiente o gerenciamento de processos de negócio da Cadeia de Suprimentos (CS) (GOMES e RIBEIRO, 2004; BALLOU, 2006; NOVAES, 2007, CHING, 2010; HARA, 2011).

De acordo com Pires (2009), a CS integra o gerenciamento de todos os processos atribuídos a empresa focal, conectados com os seus clientes, com os seus fornecedores e consigo mesma. Sendo assim, o gerenciamento da relação entre os elos da Cadeia deve estar correlacionado entre pessoas, metodologias e tecnologias empregadas nos processos das organizações envolvidas, a fim de permitir a eficiência e eficácia na Gestão da Cadeia de Suprimentos (GCS), conforme Novaes (2007), Ching (2010) e Hara (2011). Isso possibilita às pessoas envolvidas nos processos de negócio-chave da organização foco, adaptar o gerenciamento das suas atividades em seus silos funcionais, afetando seu desempenho competitivo em um contexto de conflito, incerteza e rivalidade de transações comerciais nos elos da CS (Zanoni et al., 2013; Bruna Junior et al., 2013).

Todo esse contexto pode ser percebido no modelo de três elementos de Lambert et al.(1998), que destaca a estrutura da CS, os processos de negócios da CS e os componentes gerenciais da CS. Essa ênfase do modelo de Lambert et al. (1998) pode ser percebida, também, através da natureza inter-relacional das atividades da GCS e na necessidade de se trabalhar através de várias etapas para conceber e gerenciar com sucesso uma CS (Pires 2009).

Portanto, dada a relevância das questões gerenciais de processos na CS, a análise interpretativa das estratégias utilizadas por empresas componentes do Pólo de Confecções do Agreste de Pernambuco associadas à CS impulsiona a realização 
desse estudo, cujo objetivo contempla a elaboração de um diagnóstico, avaliação e proposição de melhorias com relação a gestão de processos ao longo da GCS, com base no modelo de Lambert et al. (1998) e através de uma análise SWOT. A importância dessa análise diagnóstica com proposição de melhorias, segundo Cadden e Downes (2013), explicita as organizações como competitivas quando se relacionam na CS colaborativamente, através da combinação de recursos, partilha de conhecimentos e aumento da velocidade para o mercado.

As razões que justificam o objetivo dessa pesquisa implicam no momento em que o Pólo de Confecção do Agreste de Pernambuco articula-se na produção simultânea de peças de confecção, remetendo à necessidade local em otimizar e gerir seus processos de negócios com o auxílio de novos conceitos e metodologias.

Para isso foi realizado um estudo de caso numa empresa de confecções do Agreste de Pernambuco, classificada como de grande porte, cujas atividades manufatureiras registram 4 décadas de produção no setor de peças de vestuário, distribuição e comercialização de uma linha diversificada de produtos masculinos, incluindo calças, camisas, camisetas, bermudas, roupas íntimas e gravatas, distribuídos nas seis lojas de comercialização da organização do objeto deste estudo.

O artigo está dividido em cinco seções, além desta introdução. A segunda seção apresenta uma análise sobre processos e gerenciamento de processos na GCS. A terceira seção aborda a metolodogia da pesquisa. A seção 4 apresenta o estudo de caso, enquanto a seção cinco promove uma discussão sobre a análise diagnóstica, finalizando na seção 6 com uma conclusão.

\section{REFERENCIAL TEÓRICO}

Esta seção apresenta uma sequência de modo correlato em 4 subseções, abordando aspectos conceituais sobre o processo e o gerenciamento de processos, sua importância para o negócio e à empresa estendida; unindo esses conceitos a GCS e finalizando com uma breve descrição sobre análise SWOT. 


\subsection{Processos e Gerenciamento de Processos}

De acordo com Baldam et al. (2014), um processo equivale a uma atividade ou conjunto de atividades que se origina na entrada, desenvolve-se e entrega um valor a um cliente específico na saída. Seethamraju (2012) corrobora Baldam et al. (2014) ao afirmar que a organização, quando gerida por processos, inferir-lhe-á à prática de suas atividades o cliente como prioridade.

Para Brocke e Rosemann (2013), o processo está ligado ao fornecimento de produtos (bens ou serviços), a seus clientes. Cruz (2008) atrela ao trabalho visto como um processo, uma agregação de valor ao negócio; a Association of Business Process Management Professionals - ABPMP (2009) considera o trabalho por processos, um negócio integrador, apto a reunir pessoas, metodologias e tecnologias agrupadas para atender as expectativas dos clientes e gerar retorno de investimentos às partes interessadas.

Processos compõem atividades correlacionadas, percebidas no negócio e organizadas com a finalidade de satisfazer o cliente. As regras de negócio administram essas atividades, que por sua vez estão distribuídas na classificação dos processos, a saber: processo primário, processo de suporte e processos de gerenciamento (BROCKE, ROSEMANN, 2013; ABPMP, 2009; BALDAM et al. 2014).

No processo primário, as atividades referenciadas contemplam-se como essenciais e deterministas por representar a essência de finalização de um processo específico; no processo de suporte, a peculiaridade está vinculada ao valor que este tipo de processo repassará a um outro processo e não diretamente ao cliente, enquanto o processo de gerenciamento assegura que a organização operacionalize suas funções em concordância com os seus objetivos e metas de desempenho (ABPMP, 2009; BALDAM et al., 2014).

Consoante o grau de generalidade, os processos podem passar por mudanças que facilmente ocorrem nas organizações. Se o processo for de negócios, ou seja, quando uma tarefa precisar ser refinada por um motivo cabível, a mesma pode ser transformada em um subprocesso.

A figura 1 oportuniza a visualização dos processos decompostos numa hierarquia estruturada em que, segundo a ABPMP (2009), cobrem toda a 
organização e podem ser analisados através dos níveis de Macroprocessos, Processos, Subprocessos, Atividades e Tarefas.

Figura 1 - Especialização dos processos

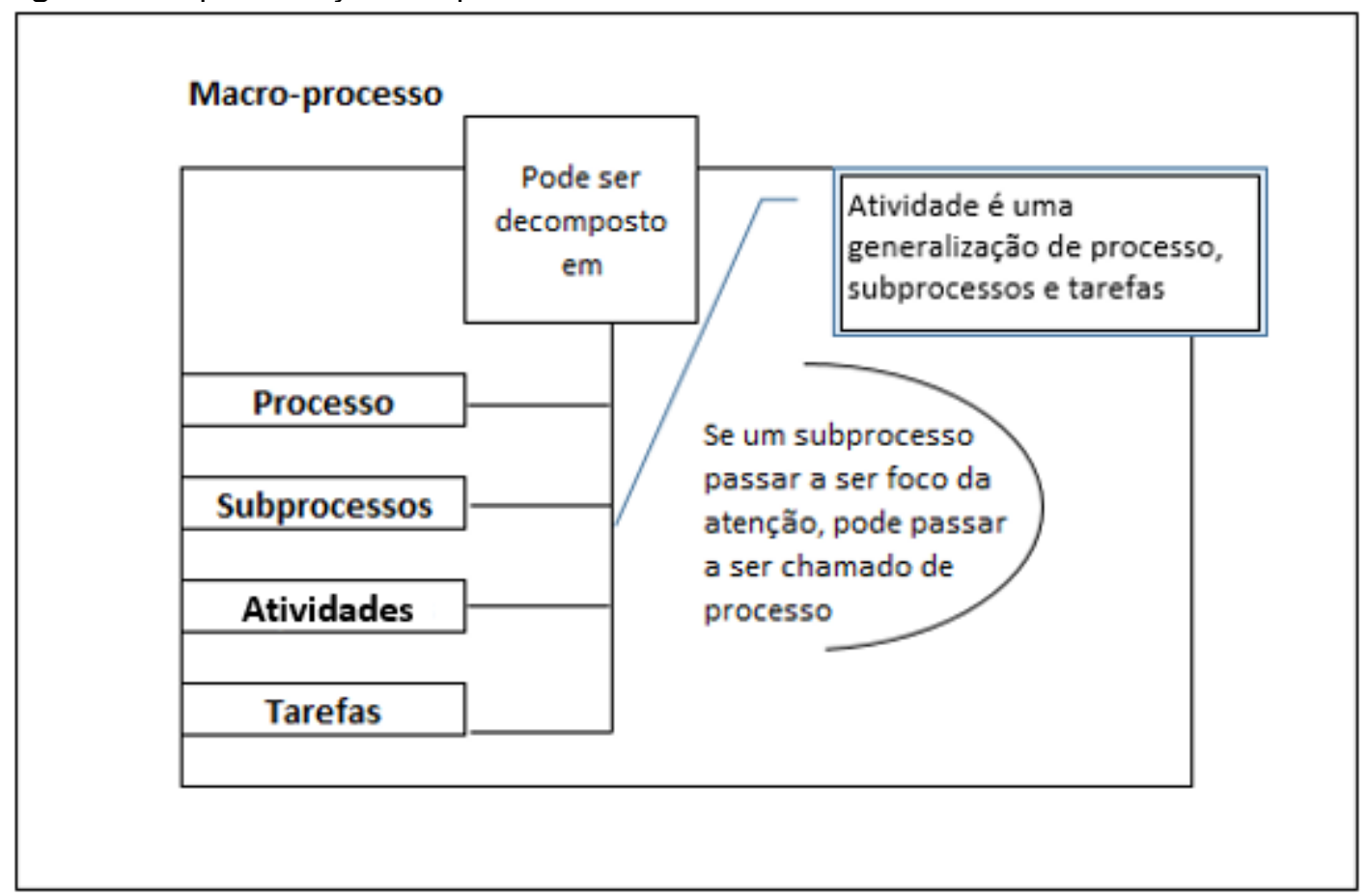

Fonte: Baldam et al. (2014) adaptado pelos autores

De acordo com a figura acima, o Macroprocesso envolve todos os processos da organização e pode ser decomposto em Processos, entendidos como um conjunto de atividades sequenciais que tomam uma entrada com o fornecedor, adiciona valor a este e produz uma saída para um cliente. O Subprocesso conectase a outro subprocesso, alcançando um objetivo alinhado ao macroprocesso, enquanto as atividades e tarefas podem ser consideradas eventos que ocorrem dentro do processo ou subprocesso.

Baldam et al. (2014) classifica os processos de acordo com seu grau de generalidade. Para a perspectiva de gerenciamento de processos, os processos são especializados em primários, de apoio e gerencial.

No gerenciamento de processos, o valor entregue ao cliente final é realizado indiretamente por integrar-se nos processos da GCS; nesta razão, o processo na organização expandida torna-se exponencial, apresentando a força econômica que um forte gerenciamento de processos pode proporcionar (SLACK et al., 2008). 
O gerenciamento de processos trouxe à GCS o desafio de maturar a integração da organização expandida na expectativa de satisfazer o seu cliente, melhorando os níveis de serviço, da qualidade e da gestão da reutilização, enquadrados nas questões internas de identificação de perdas, redução do tempo do ciclo, racionalização dos fluxos sequenciais e simplificação de regras (BROCKE e ROSEMANN, 2013).

\subsection{Gestão da Cadeia de Suprimentos}

A GCS tem sido assistencializada como conteúdo de pesquisa nos últimos anos, levando pesquisadores a multidefinições sobre o tema. Algumas definições traduzem o conceito como amplo (HARLAND et al., 1999) outras à trajetória de uma teoria que influenciará determinado autor/a (TAN, 2001).

Uma análise sintética sobre algumas definições de GCS exibe a necessidade de complementaridade, por detecção de variações que imputaram o fenômeno como incompleto. Por exemplo, a definição da GCS proposta por Ballou (2001) valoriza uma combinação de atividades a serem gerenciadas pela logística da empresa. Por outro lado, Pires (2009) expande o conceito referenciando os responsáveis por essas atividades como responsáveis pelos fluxos a Montante - fornecedores e a Jusante - cliente final, neste caso corroborado por Novaes (2007), que associa a GCS ao processo composto por diversos outros subprocessos, em que a finalização do processo de distribuição de uma organização equivale ao início do processo de suprimentos da organização seguinte.

Chopra e Meindl (2011) conceitua a GCS como sendo uma integração de todas as partes envolvidas, direta ou indiretamente, no processo ponta a ponta à realização do pedido de um cliente.

Neste sentido, uma súmula à aplicação conceitual da GCS pode ser compreendida como um conjunto de atividades na CS que reúne fornecedores, prestadores de serviços, empreendedores, agentes institucionais públicos e privados, armazéns, varejistas e os próprios clientes interligados através de fluxos de informação e de insumos por processo, até alcançar o objetivo de entregar ao cliente final o valor correspondente a um trabalho efetivo (BALLOU, 2001; NOVAES, 2007; PIRES, 2009; CHOPRA e MEINDL, 2011). 


\subsubsection{Processos da Gestão da Cadeia de Suprimentos}

Para Godoy et al. (2013), o consumidor finaliza o atendimento satisfatório à qualidade, requerendo da organização sinergia interna durante o processo para atender com eficiência e qualidade a gestão das suas atividades produtivas.

A importância dessas atividades produtivas percebidas no processo de produção equalizado a uma CS, de acordo com Pires (2009), equivale ao uso conjugado de métodos de gestão operacional e modelos de gestão estratégica estabelecidos na fase de transformação dos insumos no processo, implicando eficiência ao gerenciamento integrado dos negócios na CS e auxílio no processo de tomada de decisão operacional e estratégica, porquanto as organizações envolvidas precisam empreender.

As conjugações desses métodos são fundamentais à GCS, uma vez que sua constituição apresenta, de acordo com Bruna Junior et al. (2013), ambientes de gestão com embates, incertezas, complicações e conflitos, por conseguintes alternativas de ação não conhecidas previamente.

Por isso, é necessário conciliar à GCS metodologias que disponibilizem, através de ações de integração gerencial, a estruturação de um macroprocesso que permita expandir o entendimento do negócio por cada organização participante, para identificar objetivos que melhor representem os valores para o contexto que se propõem gerenciar (BRUNA JUNIOR et al., 2013; ZANONI et al., 2013). Nesse sentido, o uso de modelos gerenciais nos processos da GCS permite 0 aprimoramento do desempenho dos participantes na CS, uma vez que possibilita uma gestão integrada nas relações estratégicas entre os elos da CS às empresas de manufatura, fornecedores e cliente final, mediante parcerias de longo prazo (COOPER et al., 1997).

O modelo de Lambert et al. (1998) identifica na GCS uma lógica à gestão de processos na GCS, uma vez que que a descrição, análise e gerenciamento de uma GCS ocorrem com a presença da estrutura da CS, dos processos de negócios da CS e dos componentes gerenciais da GCS (Figura 2). Nesse caso, os elementos gerenciais da GCS envolvem o uso da estrutura da Cadeia à efetividade nos processos de negócios (LAMBERT et al, 1998; LAMBERT e COOPER, 2000; PIRES, 2009). 
Figura 2 - Os 03 elementos de delineamento da GCS

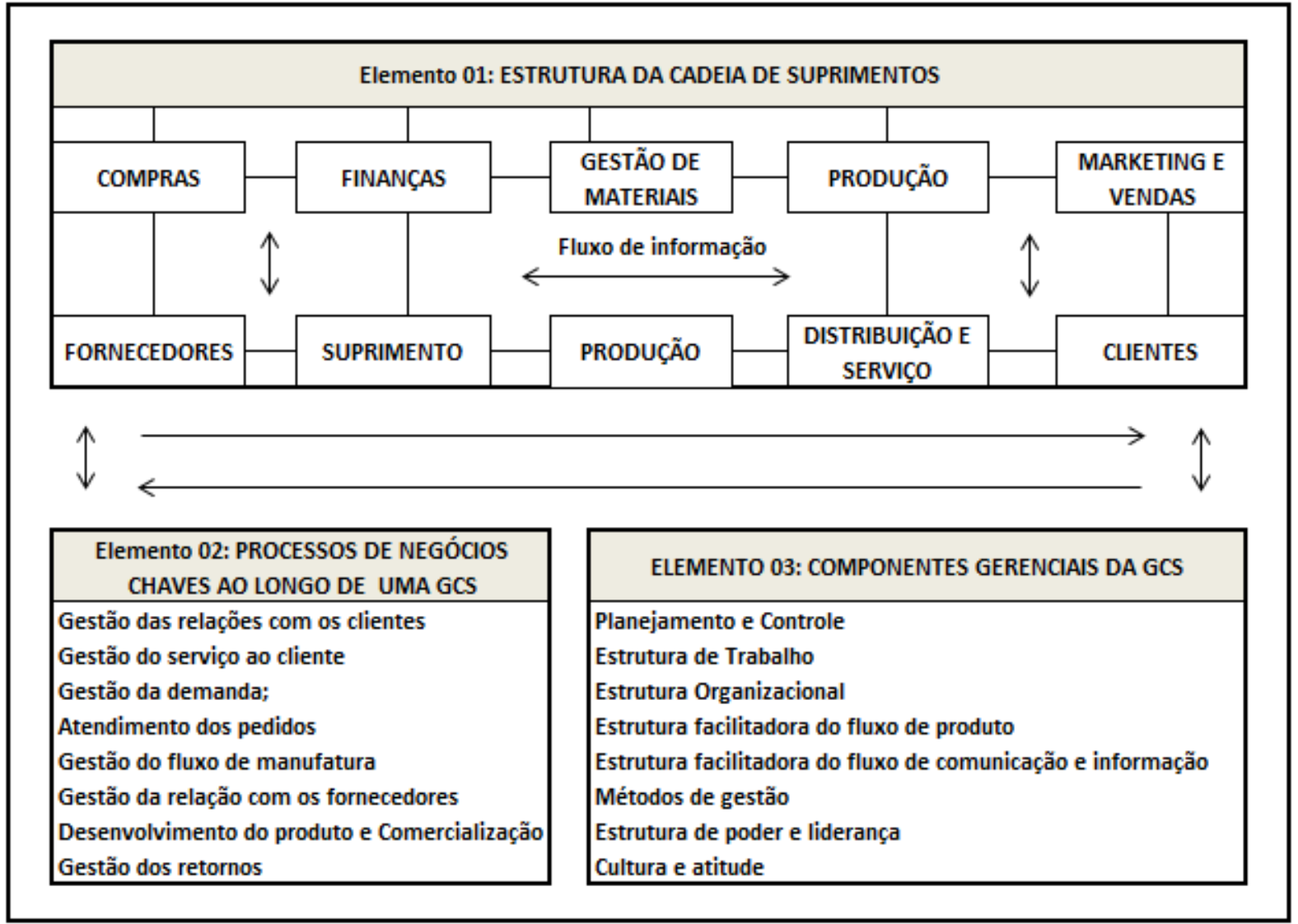

Fonte: Lambert et al. (1998). Adaptado pelos autores

De acordo com a Figura 2, o elemento 01 compreende a interligação das empresas membros na Cadeia, enquanto que o elemento 02 apresenta as atividades produtoras de output de valor para o cliente. Este, conforme Lambert et al. (1998), apresenta 8 processos de negócios, considerados estratégicos na GCS, por nivelar os elos da CS conforme suas execuções. Por fim, o elemento 03 corresponde as variáveis, através das quais os processos de negócios são administrados ao longo da CS.

\subsubsection{Gestão de Processos e Arranjo Produtivo Local (APL)}

Cassiolato e Lastres (2003) conceituam APL como um alinhamento econômico que reúne a cooperação e a interação de organizações; complementado por Cabral (2007), como uma correlação de organizações fornecedoras de equipamentos e insumos, produtoras de bens e serviços, comercializadoras, prestadoras de consultoria e clientes. Neste sentido, um APL pode ser caracterizado 
pelo expressivo número de empreendimentos localizados em determinado território, com indivíduos atuantes em torno de uma atividade produtiva predominante, consoante cooperação compartilhada e algum mecanismo de governança (Brasil, 2004).

A possibilidade conectiva de diferentes tipos de elos de processos de negócio, ao longo da GCS, estima que as dimensões estruturais de um macroprocesso de fato corrobora o conceito do APL ao integrar forças econômicas, políticas e sociais em seu contexto de atividades econômicas estruturantes às relações produtivas e de desenvolvimento entre organizações na CS (LAMBERT e COOPER, 2000; SEBRAE/ FADE, 2003).

Pires (2009) associa à gestão de processos na CS, um processo ponta a ponta que envolve a aglomeração desde o usuário final até os fornecedores primários, provedores de produtos, serviços e informações.

Esses processos aplicados podem ser entendidos como a dinâmica de um APL confluído a uma GCS (LAMBERT e COOPER, 2000; CASSIOLATO e LASTRES, 2003).

\subsection{Análise SWOT}

A análise S.W.O.T., que corresponde as Strengths (Forças), Weaknesses (Fraquezas), Opportunities (Oportunidades) e Threats (Ameaças), é considerada uma ferramenta fundamental de suporte estratégico, que facilita um estudo crítico dos fatores internos e externos à organização, permitindo ao planejamento das ações o alcance dos seus objetivos (LOBATO, 2002). Ainda segundo o autor, a análise SWOT é bastante proficiente nos segmentos de manufatura e serviço, considerando sua simplificação aplicável.

De acordo com Coimbra de Souza (2010), através do método SWOT é "[...] possível estabelecer a Postura Estratégica mais adequada a cada empresa", com base em interpretação de dados específicos concernentes ao ambiente externo e ao cenário interno das organizações. 


\section{METODOLOGIA}

Essa pesquisa foi classificada como estudo de caso, pois descreve uma aplicação prática do modelo de Lambert et al. (1998) associado a uma análise SWOT, restrita a uma organização, fornecendo conhecimento analítico sobre uma determinada realidade.

Para a elaboração diagnóstica e avaliativa à proposição de melhorias, com relação a gestão de processos ao longo da CS, esta pesquisa utilizou as etapas, conforme mostra Figura 3.

Figura 3 - Etapas da Pesquisa

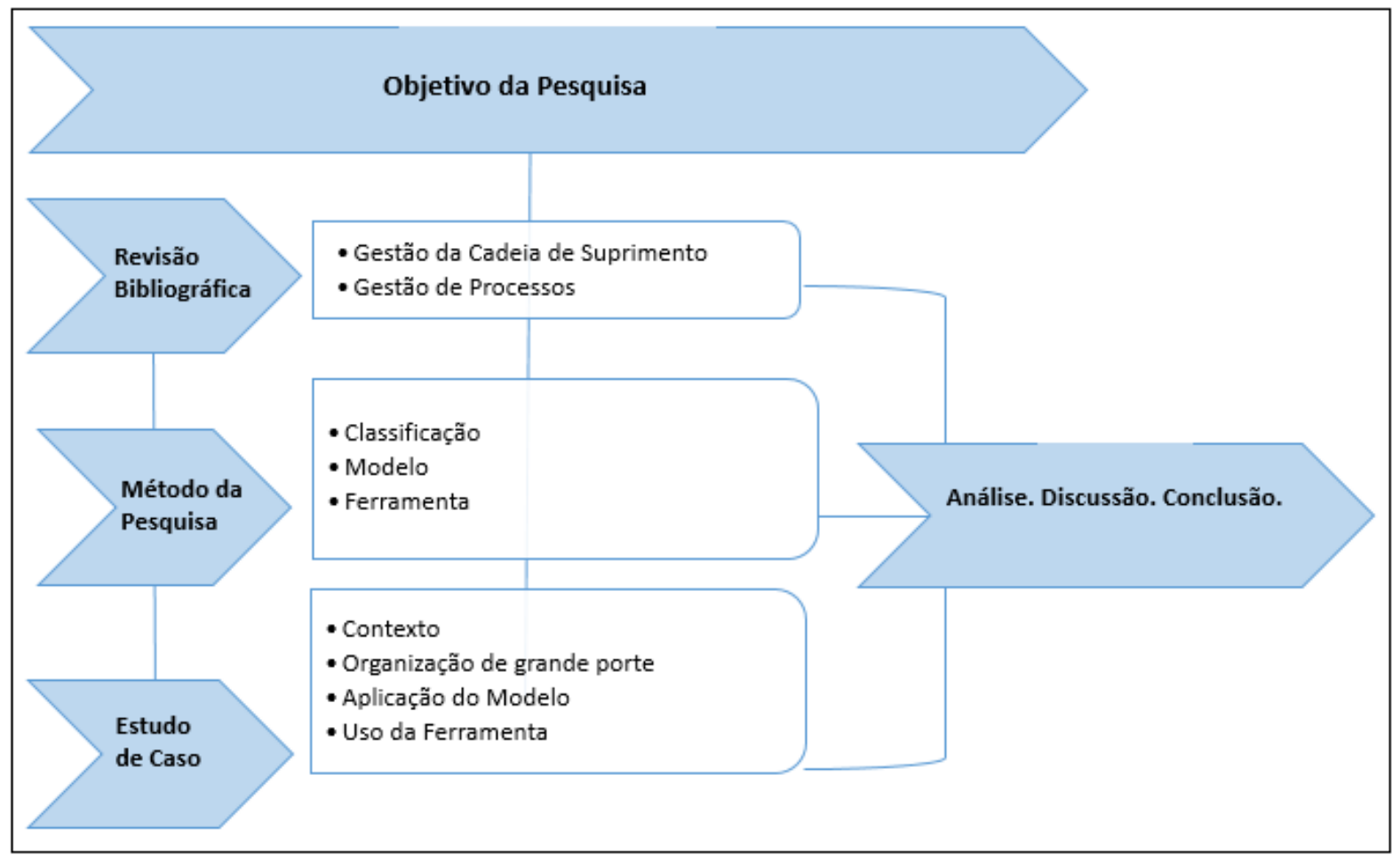

Fonte: Elaborado pelos autores

De acordo com a figura 3, os passos dessa pesquisa estão descritos abaixo:

Etapa 1 - Definição dos objetivos desse trabalho e seleção da empresa pesquisada.

Etapa 2 - Elaboração de uma revisão bibliográfica com base na GCS e na gestão de Processos.

Etapa 3 - Pontuação do método da pesquisa, constituído por sua classificação, escolha do modelo de Lambert et al. (1998) e da ferramenta de análise estratégica SWOT. 
Etapa 4 - Apresentação da organização respondente, compreendendo a explicitação do contexto do cenário externo, sua caracterização, análise das etapas dos processos produtivos, aplicação do modelo de Lambert et al. (1998) numa perspectiva comparativa com a real situação dos processos de negócio-chave na CS e análise SWOT.

Etapa 5 - Consolidação da análise, discussão dos resultados e conclusão da pesquisa.

\section{ESTUDO DE CASO}

Esta seção apresenta duas subseções. Na primeira, é apresentada a organização objeto desta pesquisa através do seu contexto, com uma acomodação sintética de informações sobre o cenário externo em que atua; na segunda subseção, este trabalho explicita a caracterização de forma sintética sobre a organização, avalia suas ações expandidas com o auxílio comparativo do modelo dos 3 elementos de Lambert et al. (1998), restrito aos elementos 2 e 3 neste trabalho, com a realidade da organização respondente. Por fim, estrutura uma matriz SWOT e discorre interpretativamente a este respeito.

\subsection{Contexto do cenário externo da organização pesquisada}

O Pólo Têxtil do Agreste Pernambucano é forte gerador de empregos, sendo um dos maiores produtores têxteis do Brasil. Em seus processos produtivos, o Pólo agrega dez municípios da Região setentrional do Agreste Pernambucano (Figura 4), concentra mais de 100 mil pessoas nos processos produtivos do setor confeccionista de peças de vestuário e entre 2000 e 2009, acresceu 56\% do seu valor ou R\$ 3,9 bilhões, equivalendo-se a 5\% do PIB de Pernambuco (SEBRAE/FADE, 2003). 
Figura 4 - Polo de Confecções de Pernambuco

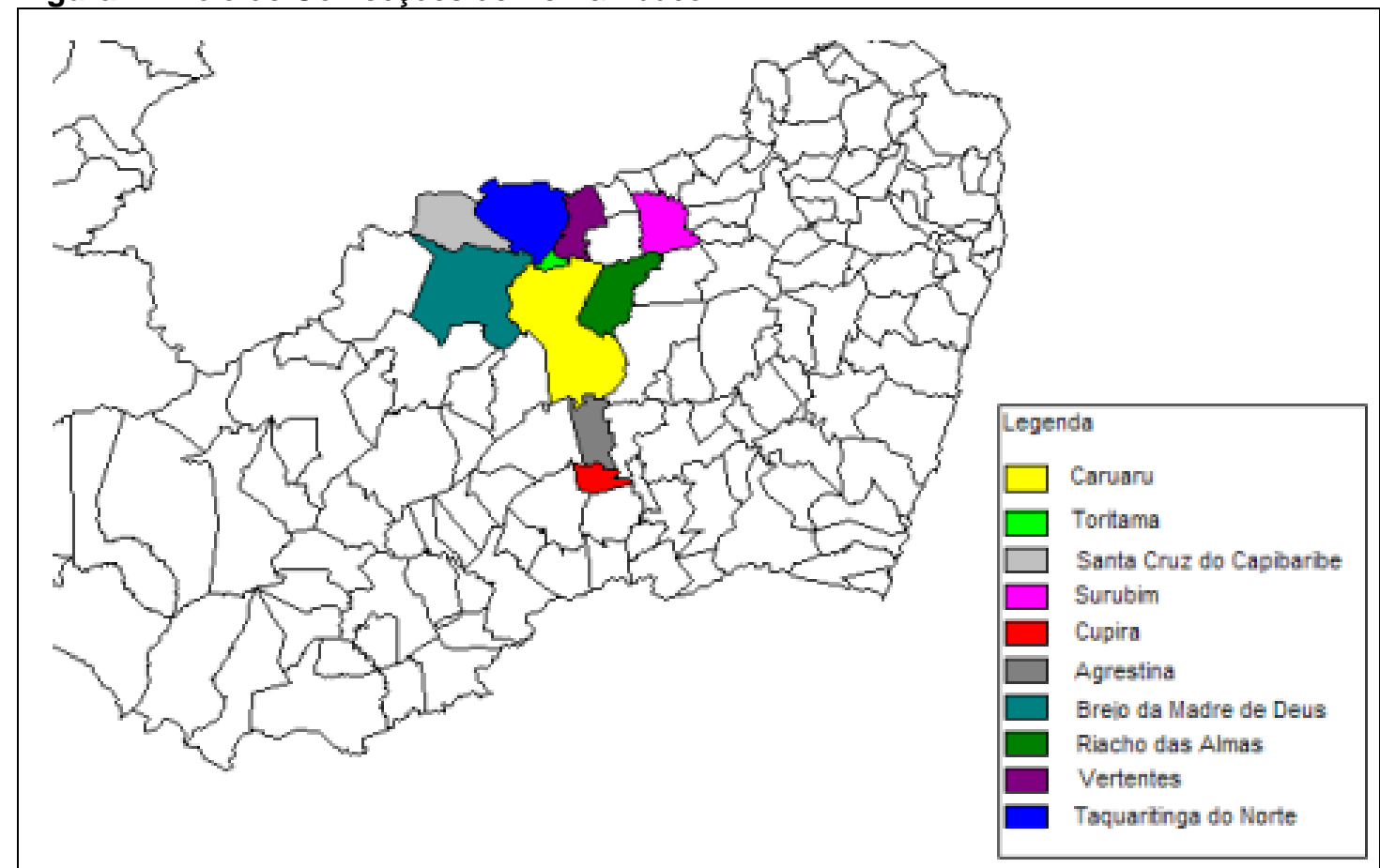

Fonte: SEBRAE/ FADE (2003)

Essas informações tornam o Polo de Confecções como um cenário de negócios dinâmico, imprevisível e competitivo, mas favorável a ações estratégicas de ação profissional nas etapas do processo produtivo confeccionista. Essas etapas, consideradas subprocessos industriais, integradas com cliente e fornecedor, exigem interação lógica na sequência operacional produtiva de peças de vestuário (BIERMANN, 2007; SEBRAE/PE, 2013).

O Polo de Confecções Agreste de Pernambuco reúne seis macroestruturas de negócios confeccionistas: O Moda Center, o Polo Comercial em Caruaru, o Parque das Feiras em Toritama e três Feiras da Sulanca nas três cidades destaques deste Polo, a saber, Santa Cruz do Capibaribe, Caruaru e Toritama, sendo detentoras da maior produção de confecções. Essas seis estruturas estão consolidadas no cenário de mutação em que se processam os negócios na CS (SEBRAE/PE, 2013).

O Moda Center de Santa Cruz do Capibaribe, visto como o maior Centro de Compras da América Latina, enquanto shopping atacadista de confecções, é estruturado por 707 lojas e seis módulos com 9.624 boxes compreendidos em uma área de 32 hectares, com $120.000 \mathrm{~m}^{2}$ de cobertura efetiva; estimando um fluxo, junto com Toritama e Caruaru, de aproximadamente 100 mil clientes de múltiplas regiões, 
com preponderância do Norte e Nordeste do Brasil, compareçam nesse local (SEBRAE/FADE, 2003).

\subsection{Caracterização sintética da organização respondente}

A empresa, foco desse estudo, trata-se de uma organização de grande porte, sólida no cenário da Região Agreste de Pernambuco e há 43 anos líder no setor confeccionista de peças de vestuário masculino.

A figura 5, abaixo, apresenta a CS de confecções da organização respondente, documentada através de visita técnica in loco à empresa, incluindo as etapas do processo produtivo de confecção de peças de vestuário discriminado por Biermann (2007).

Figura 5 - Estrutura da cadeia de suprimentos confeccionista da organização objeto deste estudo

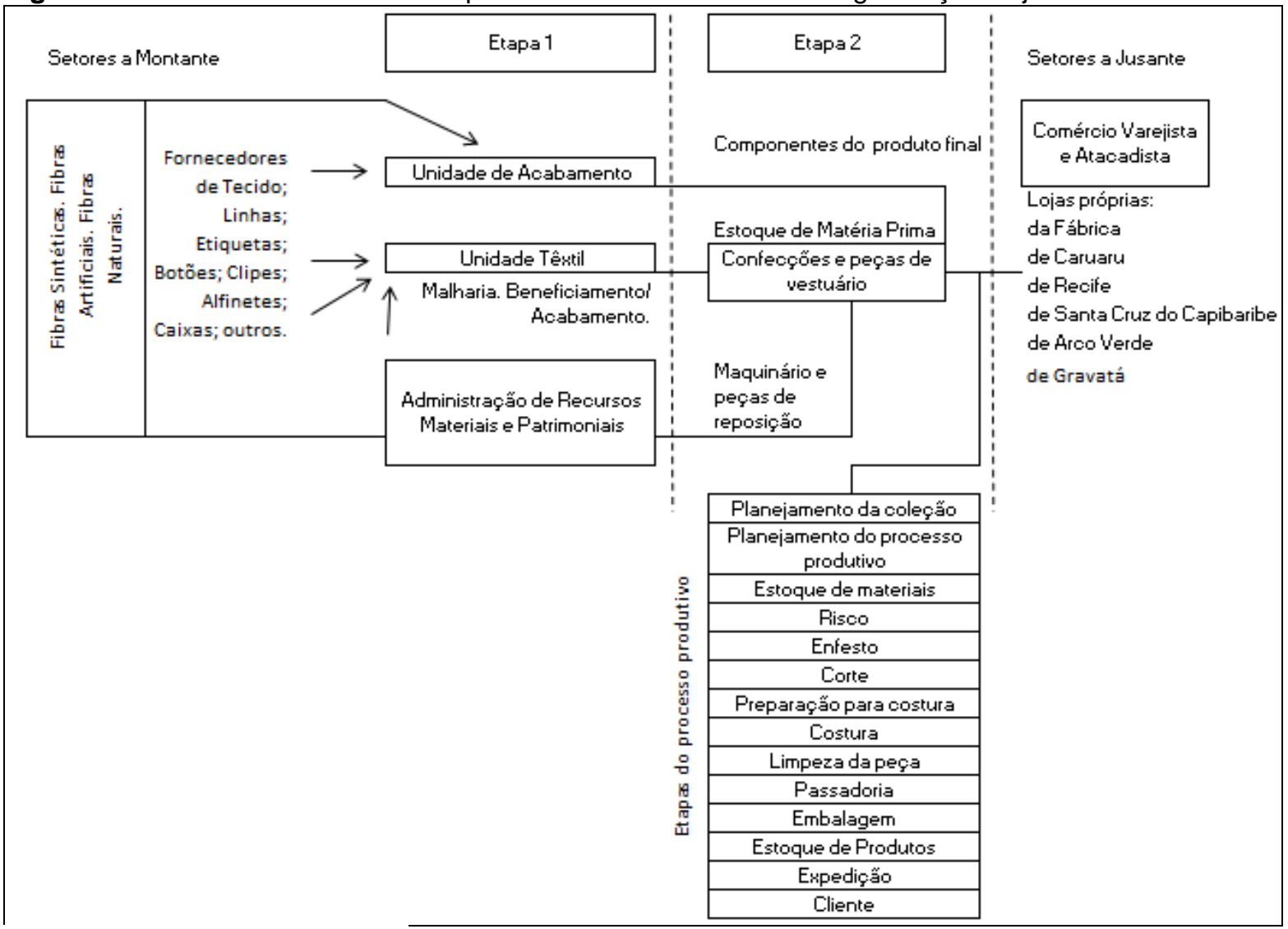

Fonte: Elaborado pelos autores

A participação a jusante dessa Cadeia apresenta 06 lojas próprias localizadas em pontos estratégicos do Polo de Confecções, com exceção da loja 03, em Recife/PE (Figura 6). O sistema de distribuição das mercadorias ocorre mediante 
relatório de pedido emitido por lojas em ação independente loja a loja, cujo estoque da fábrica é permanentemente alimentado, sem gestão de demanda, pela sua diversidade de peças de vestuário masculino para atender aos pedidos recebidos, com uso de dois transportes de modal rodoviário próprios.

$\mathrm{Na}$ figura 6, a empresa respondente apresenta a sua CS evidenciando o processo logístico de compras em conexão com o subprocesso de pedidos para atender a demanda no macroprocesso de manufatura.

Figura 6 - Cadeia de Suprimentos da Empresa pesquisada

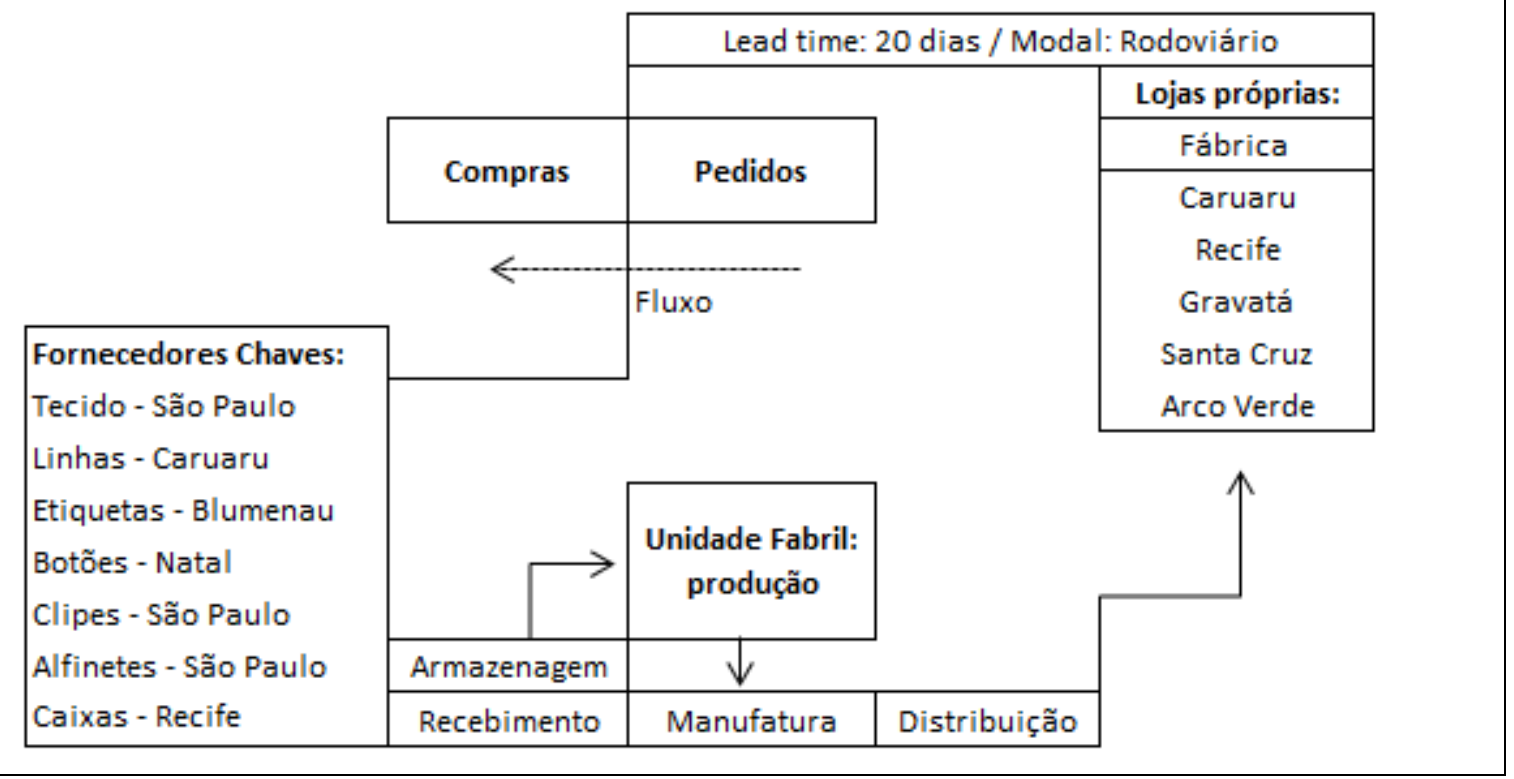

Fonte: Elaborado pelos autores

\subsection{Análise das etapas do processo produtivo da organização respondente}

Conforme a estrutura da CS da organização estudada, a figura 5 acima apresenta duas etapas produtivas condicionadas a esta empresa. $\mathrm{Na}$ etapa um, de correspondência com os processos ao longo da GCS, a empresa apresentou uma fidelização com seus fornecedores chaves, salvo ausência de um sistema de gestão de estoque e presença de elos com a empresa caracterizada pelo tempo de relacionamento na provisão de maquinário, reposição de peças, tecidos, linhas, etiquetas, botões, clipes, alfinetes e caixas.

A análise in loco considerou à etapa dos processos produtivos da empresa etapa dois, uma equivalência com o modelo estruturado por Biermann (2007), o qual determina o processo de confecção referente a uma peça de vestuário. Portanto, 
aliada a necessidade do mercado e a capacidade produtiva da empresa, essa equivalência permitiu consolidar o planejamento da coleção e do seu processo produtivo, estruturando as atividades de manufatura através da cronologia lógica de operação do estoque de materiais, risco, enfesto, corte, preparação para costura, costura, limpeza da peça, passadoria, embalagem, estoque de produtos, expedição e cliente final; no entanto, a prática observada no processo de confecção das peças de vestuário na fábrica não procede com o desenho lógico das etapas do processo produtivo. Por fim, o lead time estimado, com sistema tradicional de gestão de compras e uso do modal rodoviário para todos os fornecedores chaves à reposição de matéria prima semiacabada na empresa, gira em torno de 20 dias.

Com base nessa visita in loco, foi constatada a ausência de gerenciamento dos riscos logísticos, baixo nível de gerenciamento ao longo da sua Cadeia e incipiência sobre o planejamento do projeto de externalização em GCS. Foi percebido, também, que a CS da empresa pesquisada não apresenta em seu processo logístico de compras uma gestão efetiva nesta unidade interna de negócio, fator comprometedor para o macroprocesso de manufatura da organização que, aliado a ausência de um sistema de informação gerencial, inibe a integração plena dos silos funcionais com os elos de primeira instância na sua CS.

\section{4 .4 Comparativo com o modelo de Lambert et al. (1998)}

A figura 6 integra a estrutura da cadeia produtiva de confecções da empresa em estudo, que por sua vez possibilita uma revisão conivente aos benefícios correspondente à proposta do modelo de Lambert et al. (1998). Neste caso, o modelo molda a organização respondente a estrutura das atividades primárias e de suporte logísticos, concebendo aos processos de negócios chaves a capacidade de integrar os elos da Jusante e da Montante, auxiliados pelos componentes gerenciais no gerenciamento dos fornecedores chaves, da manufatura de confecções e das lojas próprias no grupo empresarial, estimando agregar valor à CS.

Com a implantação do modelo de 03 elementos de Lambert et al. (1998) nesta CS, existe a possibilidade de agregar valor para o cliente final através do fortalecimento entre os elos ao longo da GCS. Portanto, foram realizadas análises comparativas e de equivalência com vistas a melhoramentos na GCS. 
Os Quadros 1 e 2 apresentam esta comparação, atribuindo à lógica do modelo de Lambert et al. (1998) a realidade observada na CS da empresa em estudo.

Quadro 1 - Comparativo entre os Processos de Negócios Chaves com a Empresa em estudo

\begin{tabular}{|c|c|c|}
\hline $\begin{array}{l}\text { Processos de Negócio } \\
\text { Cadeia de Suprimentos }\end{array}$ & Lambert et al. (1998) & Empresa em estudo \\
\hline $\begin{array}{l}\text { Gestão das relações com os } \\
\text { clientes. }\end{array}$ & $\begin{array}{l}\text { Identificação dos clientes } \\
\text { perfilados; mensuração de } \\
\text { retorno sobre o que o cliente } \\
\text { proporciona. }\end{array}$ & $\begin{array}{l}\text { Gestão sintética do produto } \\
\text { e comercialização }\end{array}$ \\
\hline Gestão do serviço ao cliente. & $\begin{array}{l}\text { Cumprimento eficiente das } \\
\text { promessas; assistência pós- } \\
\text { venda. }\end{array}$ & $\begin{array}{l}\text { Cumprimento eficiente das } \\
\text { promessas; não há pós- } \\
\text { venda. }\end{array}$ \\
\hline Gestão da demanda. & $\begin{array}{l}\text { Equilibro entre a demanda do } \\
\text { cliente com a capacidade da } \\
\text { empresa fornecedora }\end{array}$ & $\begin{array}{l}\text { Não há Gestão de } \\
\text { demanda, mas estimativa } \\
\text { por sazonalidade. }\end{array}$ \\
\hline Atendimento dos pedidos. & $\begin{array}{l}\text { Atividade que requer } \\
\text { integração entre fornecedores, } \\
\text { distribuidores e operadores } \\
\text { logísticos à promoção do } \\
\text { atendimento do pedido com } \\
\text { eficiência. }\end{array}$ & $\begin{array}{l}\text { Cadeia de valor } \\
\text { estabelecida pelos fluxos } \\
\text { próprios a partir da } \\
\text { manufatura de confecções } \\
\text { e peças de vestuário. }\end{array}$ \\
\hline $\begin{array}{l}\text { Gestão do fluxo de } \\
\text { manufatura. }\end{array}$ & $\begin{array}{l}\text { Efeito de puxar a demanda, } \\
\text { com base nas necessidades } \\
\text { dos clientes (flexibilidade } \\
\text { produtiva). }\end{array}$ & $\begin{array}{l}\text { Padrão estabelecido pelo } \\
\text { mercado; produção com } \\
\text { excedente (estoque), com } \\
\text { base em previsão de } \\
\text { estoque - dados históricos. }\end{array}$ \\
\hline $\begin{array}{l}\text { Gestão da relação com os } \\
\text { fornecedores. }\end{array}$ & $\begin{array}{l}\text { Desenvolvimento de parcerias } \\
\text { com fornecedores chaves à } \\
\text { resistência sobre fluxos de } \\
\text { manufatura e desenvolvimento } \\
\text { do produto e comercialização. }\end{array}$ & $\begin{array}{l}\text { Parcerias efetivas entre os } \\
\text { fornecedores chaves. }\end{array}$ \\
\hline $\begin{array}{l}\text { Desenvolvimento do produto } \\
\text { e comercialização. }\end{array}$ & $\begin{array}{l}\text { Trabalho conjunto entre } \\
\text { clientes e fornecedores à } \\
\text { aquisição de time-to-market. } \\
\text { Interface com a gestão das } \\
\text { relações com os clientes, com } \\
\text { os fornecedores e com os } \\
\text { fluxos de manufatura. }\end{array}$ & $\begin{array}{l}\text { Desenvolvimento sintético } \\
\text { do produto e } \\
\text { comercialização. }\end{array}$ \\
\hline Gestão dos retornos. & Único com sentido Montante. & $\begin{array}{l}\text { Não há gestão dos } \\
\text { retornos. }\end{array}$ \\
\hline
\end{tabular}

Fonte: Elaborado pelos autores 
Quadro 2 - Comparativo entre Negócios Chaves com a Empresa em estudo

\begin{tabular}{|c|c|c|}
\hline $\begin{array}{c}\text { Componentes de Negócios } \\
\text { SC }\end{array}$ & Lambert et al. (1998) & Empresa em estudo \\
\hline $\begin{array}{l}\text { Planejamento e controle das } \\
\text { operações. }\end{array}$ & $\begin{array}{l}\text { Planejamento colaborativo e } \\
\text { métricas de avaliação de } \\
\text { desempenho GCS. }\end{array}$ & $\begin{array}{l}\text { Planejamento e controle } \\
\text { sintético das operações. }\end{array}$ \\
\hline Estrutura de trabalho. & $\begin{array}{l}\text { Indicador de eficiência sobre } \\
\text { a realização de tarefas e } \\
\text { atividades. }\end{array}$ & $\begin{array}{l}\text { Estrutura sintética de } \\
\text { trabalho }\end{array}$ \\
\hline Estrutura Organizacional. & $\begin{array}{l}\text { Integração dos processos na } \\
\text { GCS. }\end{array}$ & $\begin{array}{l}\text { Não há estrutura } \\
\text { organizacional. }\end{array}$ \\
\hline $\begin{array}{l}\text { Estrutura facilitadora do fluxo } \\
\text { de produtos. }\end{array}$ & $\begin{array}{l}\text { Eficácia no abastecimento, } \\
\text { manufatura e distribuição. }\end{array}$ & $\begin{array}{l}\text { Estrutura facilitadora do fluxo } \\
\text { de produtos existente. }\end{array}$ \\
\hline $\begin{array}{l}\text { Estrutura facilitadora do fluxo } \\
\text { de comunicação e } \\
\text { informação. }\end{array}$ & $\begin{array}{l}\text { Conexões entre os elos da } \\
\text { GCS }\end{array}$ & $\begin{array}{l}\text { Estabelecido com os } \\
\text { fornecedores chaves }\end{array}$ \\
\hline Métodos de Gestão. & $\begin{array}{l}\text { Filosofia corporativa e } \\
\text { técnicas de gestão em toda } \\
\text { GCS. }\end{array}$ & Não há métodos de Gestão. \\
\hline $\begin{array}{l}\text { Estrutura do poder e da } \\
\text { liderança. }\end{array}$ & $\begin{array}{l}\text { Jogo de forças entre elos da } \\
\text { GCS }\end{array}$ & $\begin{array}{l}\text { Estrutura sintética do poder } \\
\text { e da liderança. }\end{array}$ \\
\hline Cultura e atitude. & $\begin{array}{l}\text { Valorização do capital } \\
\text { humano e incorporação na } \\
\text { gestão da empresa. }\end{array}$ & $\begin{array}{l}\text { Métodos tradicionais de } \\
\text { Gestão. }\end{array}$ \\
\hline
\end{tabular}

Fonte: Elaborado pelos autores

A equivalência dos processos de Negócios Chaves e Componentes de Negócios Chaves de Lambert et al. (1998) com os processos da empresa objeto deste estudo sequenciam a análise S.W.O.T avaliativa e diagnóstica, seguida de sugestões de melhorias, conforme consta no Quadro 3 a seguir. 
Quadro 3 - Análise SWOT

\begin{tabular}{|c|c|c|c|c|}
\hline $\begin{array}{l}\text { Modelo de Lambert } \\
\text { et al. (1998) }\end{array}$ & Forças & Fraquezas & Oportunidades & Ameaças \\
\hline $\begin{array}{l}\text { Gestão das relações } \\
\text { com os clientes }\end{array}$ & & $\begin{array}{l}\text { Não há um } \\
\text { controle efetivo de } \\
\text { mensuração de } \\
\text { retorno sobre o } \\
\text { que o cliente } \\
\text { proporciona. }\end{array}$ & & $\begin{array}{l}\text { A pressão de } \\
\text { mercado por } \\
\text { flexibilidade e } \\
\text { reatividade }\end{array}$ \\
\hline $\begin{array}{l}\text { Gestão do serviço ao } \\
\text { cliente }\end{array}$ & $\begin{array}{l}\text { Cumprimento } \\
\text { eficiente das } \\
\text { promessas }\end{array}$ & & Não há pós-venda & \\
\hline Gestão da demanda & & $\begin{array}{l}\text { Estimativa por } \\
\text { sazonalidade }\end{array}$ & $\begin{array}{l}\text { Investimento em } \\
\text { sistema de gestão e } \\
\text { aquisição de mão } \\
\text { de obra } \\
\text { especializada }\end{array}$ & \\
\hline $\begin{array}{l}\text { Atendimento dos } \\
\text { pedidos }\end{array}$ & $\begin{array}{l}\text { Capilaridade } \\
\text { presente nos } \\
\text { principais } \\
\text { centros de } \\
\text { compras do } \\
\text { Polo. }\end{array}$ & & $\begin{array}{l}\text { Disponibilidade de } \\
\text { capacitação } \\
\text { profissional para } \\
\text { operadores } \\
\text { logísticos em } \\
\text { Instituições de } \\
\text { Ensino Superior na } \\
\text { Região }\end{array}$ & $\begin{array}{l}\text { Cadeia de valor } \\
\text { estabelecida por } \\
\text { fluxos próprios a } \\
\text { partir da } \\
\text { manufatura de } \\
\text { confecções e } \\
\text { peças de } \\
\text { vestuário }\end{array}$ \\
\hline $\begin{array}{l}\text { Gestão do fluxo de } \\
\text { manufatura }\end{array}$ & & $\begin{array}{l}\text { Padrão } \\
\text { estabelecido pelo } \\
\text { mercado; } \\
\text { produção de } \\
\text { excedente } \\
\text { (estoque), com } \\
\text { base em previsão } \\
\text { de estoque - } \\
\text { dados históricos. }\end{array}$ & $\begin{array}{l}\text { Construção de } \\
\text { vínculo entre } \\
\text { capacidade } \\
\text { estratégica e de } \\
\text { processos. }\end{array}$ & \\
\hline $\begin{array}{l}\text { Gestão da relação } \\
\text { com os fornecedores }\end{array}$ & $\begin{array}{l}\text { Relacioname } \\
\text { nto efetivo } \\
\text { com os } \\
\text { fornecedores } \\
\text { chaves }\end{array}$ & $\begin{array}{l}\text { Ausência de } \\
\text { Banco de Dados }\end{array}$ & $\begin{array}{l}\text { Desenho e } \\
\text { modelagem de } \\
\text { processos }\end{array}$ & $\begin{array}{l}\text { Conhecimento } \\
\text { sobre gestão de } \\
\text { processos }\end{array}$ \\
\hline $\begin{array}{l}\text { Desenvolvimento do } \\
\text { produto e } \\
\text { comercialização }\end{array}$ & & $\begin{array}{l}\text { Ausência de time- } \\
\text { to-market. }\end{array}$ & $\begin{array}{l}\text { Inovação e } \\
\text { desenvolvimento. }\end{array}$ & \\
\hline $\begin{array}{l}\text { Gestão dos } \\
\text { retornos }\end{array}$ & & $\begin{array}{l}\text { Ausência de } \\
\text { gestão reversa }\end{array}$ & $\begin{array}{l}\text { Estratégias para } \\
\text { desenvolvimento } \\
\text { de tecnologias } \\
\text { ecologicamente } \\
\text { equilibradas }\end{array}$ & \\
\hline
\end{tabular}


Quadro 3 - Análise SWOT

\begin{tabular}{|c|c|c|c|c|}
\hline $\begin{array}{l}\text { Modelo de Lambert } \\
\text { et al. (1998) }\end{array}$ & Forças & Fraquezas & Oportunidades & Ameaças \\
\hline $\begin{array}{l}\text { Planejamento e } \\
\text { Controle de } \\
\text { Operações }\end{array}$ & & $\begin{array}{l}\text { Ausência de } \\
\text { planejamento de } \\
\text { melhorias de } \\
\text { processos }\end{array}$ & & $\begin{array}{l}\text { Novos entrantes } \\
\text { com alinhamento } \\
\text { estratégico } \\
\text { expansão do } \\
\text { negócio }\end{array}$ \\
\hline Estrutura de trabalho & & $\begin{array}{l}\text { Não há indicador } \\
\text { de eficiência sobre } \\
\text { mão de obra } \\
\text { alocada }\end{array}$ & $\begin{array}{l}\text { Desenho e } \\
\text { modelagem de } \\
\text { processos }\end{array}$ & \\
\hline $\begin{array}{l}\text { Estrutura } \\
\text { Organizacional }\end{array}$ & & $\begin{array}{l}\text { Especialização e } \\
\text { foco nas } \\
\text { atividades chaves }\end{array}$ & $\begin{array}{l}\text { Está ocorrendo uma } \\
\text { pesada } \\
\text { racionalização e } \\
\text { reorganização das } \\
\text { empresas } \\
\text { operadoras de } \\
\text { logística }\end{array}$ & \\
\hline $\begin{array}{l}\text { Estrutura facilitadora } \\
\text { do fluxo de produto }\end{array}$ & & $\begin{array}{l}\text { Ausência de } \\
\text { monitoramento e } \\
\text { controle dos } \\
\text { processos }\end{array}$ & $\begin{array}{l}\text { Implementação e } \\
\text { execução de } \\
\text { processos }\end{array}$ & \\
\hline $\begin{array}{l}\text { Estrutura facilitadora } \\
\text { do fluxo de } \\
\text { comunicação e } \\
\text { informação }\end{array}$ & & $\begin{array}{l}\text { Disponibilização } \\
\text { de informações } \\
\text { fundamentais à } \\
\text { tomada de } \\
\text { decisões rápidas e } \\
\text { acertadas }\end{array}$ & & $\begin{array}{l}\text { Espetacular } \\
\text { amadurecimento } \\
\text { das tecnologias da } \\
\text { informação }\end{array}$ \\
\hline Métodos de Gestão & & $\begin{array}{l}\text { Não há métodos } \\
\text { de gestão } \\
\text { empregados nos } \\
\text { processos }\end{array}$ & $\begin{array}{l}\text { Modelos de Gestão } \\
\text { GCS e BPM como } \\
\text { tendência. }\end{array}$ & \\
\hline $\begin{array}{l}\text { Estrutura de Poder e } \\
\text { Liderança }\end{array}$ & & $\begin{array}{l}\text { Não há controle } \\
\text { interdependente } \\
\text { clareza de } \\
\text { propósito }\end{array}$ & & $\begin{array}{l}\text { Possibilidade em } \\
\text { outros Polos } \\
\text { entrarem na } \\
\text { região com } \\
\text { conexões entre } \\
\text { configurações de } \\
\text { estratégias e } \\
\text { modelos de } \\
\text { gestão GCS } \\
\text { maturados. }\end{array}$ \\
\hline Cultura e Atitude & & $\begin{array}{l}\text { Métodos } \\
\text { tradicionais de } \\
\text { gestão }\end{array}$ & $\begin{array}{l}\text { Valores e crenças } \\
\text { nos processos }\end{array}$ & \\
\hline
\end{tabular}

Fonte: Elaborado pelos autores 


\subsection{Análise SWOT}

O Quadro 4 apresenta uma visualização sintética com predominância dos pontos fortes e fracos, numa perspectiva de análise interna e com predominância das ameaças e oportunidades numa perspectiva externa de análise.

Quadro 4 - Condensação sintética diagnóstica

\begin{tabular}{|c|c|c|c|c|}
\hline \multirow{2}{*}{\multicolumn{3}{|c|}{ DIAGNÓSTICO }} & \multicolumn{2}{|c|}{ ANÁLISE INTERNA } \\
\hline & & & Predominância de FRAQUEZAS & Predominância de FORÇAS \\
\hline 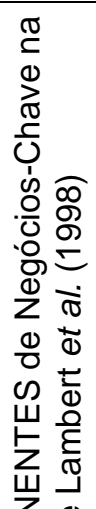 & 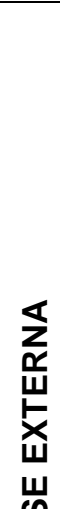 & 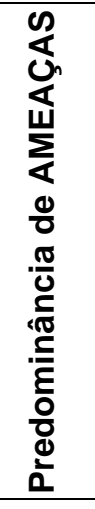 & $\begin{array}{l}\text { - Estimativa de produção por } \\
\text { sazonalidade. } \\
\text { - Inadequação de SI / TI. } \\
\text { Inaplicabilidade de modelos de } \\
\text { BPMM. } \\
\text { - Relacionamento informal com } \\
\text { fornecedores e clientes. } \\
\text { - Ausência de planejamento da } \\
\text { capacidade e da necessidade. } \\
\text { - Gestão sintética de marketing. }\end{array}$ & $\begin{array}{l}\text { - Relacionamento efetivo com } \\
\text { os fornecedores-chave. } \\
\text { - Verifica crédito de cliente. } \\
\text { - Uso de procedimento com } \\
\text { etapas pré-definidas para } \\
\text { desenvolvimento do produto. } \\
\text { - Uso de roteiro com atividades } \\
\text { definidas desde a entrada do } \\
\text { pedido até a entrega do } \\
\text { produto. }\end{array}$ \\
\hline 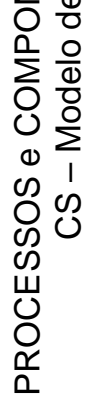 & $\frac{1}{\frac{1}{2}}$ & 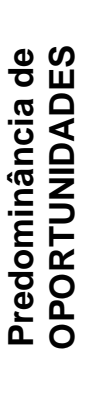 & $\begin{array}{l}\text { - Ausência de identificação entre } \\
\text { os clientes chaves dos demais } \\
\text { clientes. } \\
\text { - Não há pós-venda. } \\
\text { - Elaboração de modelo de BPM. } \\
\text { - Ausência de Banco de Dados. } \\
\text { - Gestão sintética de Marketing. } \\
\text { - Métodos tradicionais de Gestão. }\end{array}$ & $\begin{array}{l}\text { - Cumprimento eficiente das } \\
\text { promessas. } \\
\text { - Presente nos principais } \\
\text { centros de compras do Pólo } \\
\text { Têxtil. } \\
\text { - Parceria efetiva entre } \\
\text { forcenecodres chaves. }\end{array}$ \\
\hline
\end{tabular}

\begin{tabular}{|c|c|c|c|}
\hline 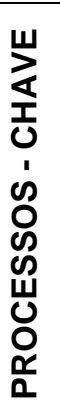 & $\begin{array}{l}\text { - Gestão das relações com os clientes. } \\
\text { - Gestão do serviço ao cliente. } \\
\text { - Gestão da demanda. } \\
\text { - Atendimento dos pedidos. } \\
\text { - Gestão do fluxo de manufatura. } \\
\text { - Gestão da relação com os } \\
\text { fornecedores. } \\
\text { - Desenvolvimento do produto e } \\
\text { comercialização. } \\
\text { - Gestão dos retornos. }\end{array}$ & 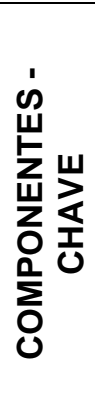 & $\begin{array}{l}\text { - Gestão das relações com os clientes. } \\
\text { - Estrutura de trabalho. } \\
\text { - Estrutura Organizacional. } \\
\text { - Estrutura facilitadora do fluxo de } \\
\text { produtos. } \\
\text { - Estrutura facilitadora do fluxo de } \\
\text { comunicação e informação. } \\
\text { - Métodos de Gestão. } \\
\text { - Estrutura do poder e da liderança. } \\
\text { - Cultura e atitude. }\end{array}$ \\
\hline
\end{tabular}

Fonte: Elaborado pelos autores

Com base nessa análise SWOT, foram levantadas algumas diretrizes que poderiam ser executadas na organização. Essas diretrizes foram baseadas através das seguintes análises: 
- Cruzamento entre oportunidades e pontos fortes para definir as estratégias que promoverão a diferenciação e o sucesso da organização;

- Cruzamento entre dificuldades/ameaças e pontos fortes representando a possibilidade de se investir na modificação do ambiente, de modo a torna-lo mais favorável a organização;

- Cruzamento entre oportunidades e pontos fracos para estabelecer as bases para modificação no ambiente interno, de modo a aproveitar melhor as oportunidades;

- Cruzamento entre dificuldades/ameaças e pontos fracos para detectar se existem situações de alta relevância para a organização, gerando necessidades de modificações mais profundas.

\section{ANÁLISE E DISCUSSÃO DOS RESULTADOS}

A empresa objeto deste estudo reflete uma realidade sobre a presença de práticas de gestão familiar, quando a ideia atrelada aos seus processos deverá ser as práticas de profissionalismo no exercício dos processos integralizados, operacionalizados com eficiência e eficácia de gerenciamento dos negócios para a satisfação do cliente final.

Em correspondência com os processos ao longo da GCS, a empresa apresentou uma fidelização com seus fornecedores chaves, salvo ausência de um sistema de gestão de estoque e presença de elos com a empresa caracterizada pelo tempo de relacionamento. Com relação ao lead time, este possivelmente prorroga o tempo 'ótimo' para a reposição de matéria prima semiacabada na empresa em função de um sistema tradicional de gestão de compras. Com isso, o estoque da fábrica é permanentemente alimentado, sem gestão de demanda e com significativa diversidade de peças de vestuário masculino para atender aos pedidos recebidos, com uso de dois transportes de modal rodoviário próprios.

Isto implica em estabelecer o apoio da alta direção à aquisição de metodologias e tecnologias adequadas ao alinhamento dos processos com a estratégia do negócio, a capacitação das pessoas e a gestão da mudança, cujos objetivos correspondem a aprimorar o desempenho da organização, melhorar as 
práticas de trabalho, desenvolvimento e entendimento das pessoas participantes na organização. Porém, a aplicação desses modelos com referência à GCS, considera a necessidade de integração, conforme Brocke e Rosemann (2013), dos elementos participantes em todos os processos da Cadeia, clientes, fornecedores, parceiros, influenciadores e funcionários. Neste sentido, o gerenciamento dos processos deverá contemplar o desenvolvimento dos recursos humanos, de produção, de tecnologia e financeiro à produção de valor com vistas à satisfação do cliente final (CHOPRA, 2011; PIRES, 2009; LOCKAMY III e MCCORMACK, 2004).

Portanto, o presente trabalho evidencia a necessidade de equivalência dos processos da CS com o modelo de Lambert et al. (1998). Nesse caso, a relevância deste estudo compreende a flexibilidade operacional e reatividade informacional sobre o cumprimento dos processos a Montante e a Jusante, com relação à gestão dos processos de manufatura e serviços ao longo de toda CS. Isto porque a organização deve possuir em sua estratégia de visão, a inteireza do seu ambiente interno, de suas operações externas e das atuações de cada elemento participante na Cadeia.

\section{CONCLUSÃO}

O resultado desta análise autentica a relevância desse trabalho sob 3 aspectos preliminares: I) A organização em estudo precisa identificar, formalmente, seus processos de negócios chave na CS e correlacioná-los com seus silos verticais; II) A organização em estudo deve apropriar-se dos componentes gerenciais ao longo da CS para assegurar-se do melhoramento contínuo dos seus processos e, III) A organização pesquisada deve adotar modelos conceituais adequados à sua gestão ao longo da CS, efetivando a gestão de mudanças auxiliada por procedimentos de maturidade sobre seus processos ponta a ponta.

Com isso, as organizações do APL Têxtil do Agreste de Pernambuco devem se relacionar na CS de forma estratégica, adotando modelos conceituais, estruturando seus silos verticais a partir de uma gestão de processos chaves de negócios na CS, identificando possíveis parcerias entre os elos de processos com fluxos sequenciados; dada a importância da existência e manutenção dos fluxos de 
informação, produção, serviços e fornecedores integrados na CS, com vistas à satisfação do cliente.

Nesse sentido, as organizações do APL Têxtil do Agreste de Pernambuco devem formalizar um ou mais conteúdo/s metodológico/s e tecnológico/s que se adequem a possibilitar o fomento do ideal de gestão integrada nas relações estratégicas entre os elos da CS, em menção às organizações têxteis do setor de peças de confecção mediante parcerias de longo prazo entre participantes correlatos no processo de suprimento ao cliente final, por conseguinte aperfeiçoamento do desempenho dos participantes na Cadeia de Suprimentos.

\section{REFERÊNCIAS}

ABPMP (2009). BPM CBOK guia para o gerenciamento de processos de negócios: corpo comum de conhecimento. 2. ed.

BALDAM, R.; VALLE, R.; ROZENFELD, Henrique. Gerenciamento de processos de negócios BPM: Uma referência para implantação prática. 1. ed. Rio de Janeiro: Elsevier, 2014

BALLOU, R.H. Gerenciamento da cadeia de suprimentos: planejamento, organização e logística empresarial. 4. ed. Porto Alegre: Bookman, 2001.

Gerenciamento da cadeia de suprimentos: logística empresarial. 5ed.

Porto Alegre: Bookman, 2006.

BIERMANN, M. J. E. Gestão do processo produtivo. Porto Alegre: SEBRAE/RS, 2007.

BRASIL. 2004. Termo de referência para política nacional de apoio ao desenvolvimento de arranjos produtivos locais. Versão Final do GT Interministerial, Ministério do Desenvolvimento, Indústria e Comércio Exterior (MDIC) 2014.

BROCKE, J. V.; ROSEMANN, M. Manual de BPM: gestão de processos de negócio. Porto Alegre: Bookman, 2013.

BRUNA JUNIOR, E. D.; ENSSLIN, L; ENSSLIN, S. R. Gestão de Desempenho na Cadeia de Suprimentos Interna de uma Companhia de Equipamentos para Refrigeração, Revista Produção Online, Florianópolis, SC, v.13, n. 3, p. 785-813, jul./set. 2013.http://dx.doi.org/10.14488/1676-1901.v13i3.890. Disponível em:< http://www.producaoonline.org.br/rpo/article/view/890>. Acesso em 03 nov. 2014.

CADDEN, Trevor; DOWNES, Stephen John Downes. Developing a business process for product development. Business Process Management Journal. v. 19, n. 4, p. 715-736, 2013. DOI 10.1108/BPMJ-Jan-2012-0006

CASSIOLATO, J. E.; LASTRES, H. M. M. Glossário de arranjos e sistemas produtivos e inovativos locais. SEBRAE-RJ. 2003. 
CHOPRA, S.; MEINDL, P. Gestão da cadeia de suprimentos: estratégia, planejamento e operações. 4ed. São Paulo: Pearson Prentice Hall, 2011.

CHING, Y. H, Gestão de estoques na cadeia de logística integrada: supply chain. 4. ed. São Paulo: Atlas, 2010.

COIMBRA DE SOUZA, S. D.; LOBO, P. E. M.; Manhães, C. H.P. Conjugação da Curva de Pareto com a Matriz BCG para Definição de Estratégias de Produto em duas Unidades de Fast Food. Revista Produção Online, v.10, n.4, p. 818-836, dez., 2010. Disponível em: < http://www.producaoonline.org.br/rpo/article/view/483>. Acesso em 03 nov. 2014.

http://dx.doi.org/10.14488/1676-1901.v10i4.483

CABRAL, . M. Relações possíveis entre empreendedorismo, arranjos organizacionais e institucionais: estudo de casos múltiplos no Pólo de Confecções do Agreste Pernambucano. 2007. 306 f. Tese (Doutorado em Administração) - Universidade Federal da Bahia, Salvador, 2007.

COOPER, M. C.; LAMBERT, D. M.; PAGH, J. D.Supply Chain Management: More Than a New Name for Logistics. The International Journal of Logistics Management, v. 8, n. 1, p. 1-14, 1997. http:// dx.doi.org/10.1108/09574099710805556

CRUZ, Tadeu. BPM \& BPMS: Business Process Management \& Business Process Management Systems. Rio de Janeiro: Brasport, 2008.

GALDAMÉZ, E. V. C. \& CARPINETTI, L. C. R. \& GEROLAMO, M. C. Proposta de um sistema de avaliação do desempenho para arranjos produtivos locais. Gest. Prod., São Carlos, v. 16, n. 1, p. 133-151, jan./mar. 2009.

GODOY, L. P.; CHAPOVAL NETO, A.; LORENZETT, D. B.; GUARIENTI, E. P. Melhoria Contínua dos Processos e Combate ao Desperdício Através da Ferramenta QFD: o caso da metalúrgica. Revista Produção Online, Florianópolis, SC, v.13, n. 2, p. 417-449, abr./jun. 2013. DOI: http://dx.doi.org/10.14488/1676-1901.v13i2.974. Disponível em: < http://www.producaoonline.org.br/rpo/article/view/974>. Acesso em: 03 nov. 2014.

GOMES, C. F. S.; RIBEIRO, P. C. C. Gestão da cadeia de suprimentos integrada à tecnologia da informação. São Paulo: Thomson, 2004.

HARA, C. M. Logística: armazenagem, distribuição e trade. 4 ed. Campinas: Alínea, 2011

HARLAND, C. M.; LAMMING, R. C.; COUSINS, P. D., Developing the concept of supply strategy. International Journal of Operations \& Production Management, v.19, n.7, p.650-669, 1999. http://dx.doi.org/10.1016/j.jom.2007.01.004

LAMBERT, D. M.; COOPER, M. C.; PAGH, J. D. Supply chain management: implementation issues and research opportunities. International Journal of Logistics Management, v. 9, n. 2, p. 1-19, 1998a. http://dx.doi. org/10.1108/09574099810805807

LAMBERT, D. M.; COOPER, M. C. Issues in supply chain management. Industrial Marketing Management, v. 29, p. 65-83, 2000.

LOBATO, David Menezes. Administração estratégica: uma visão orientada para a busca de vantagens competitivas. Rio de Janeiro: Editoração, 2002. 
LOCKAMY III, A; MCCORMACK, K. (2004), The development of a supply chain management process maturity model using the concepts of business process orientation. Supply Chain Management: An International Journal, v.9, n.4, p. 272 - 278, 2004. http://dx.doi.org/10.1108/13598540410550019

NOVAES, A. G. Logística e gerenciamento da cadeia de distribuição: estratégia, operação e avaliação. 3. ed. Rio de Janeiro: Campus, 2007.

PIRES, S.R.I. Gestão da cadeia de suprimentos (supply chain managemente): conceitos, estratégias e casos. São Paulo: Atlas, 2009.

PUGA, F.P. Alternativas de apoio a MPME's localizadas em Arranjos Produtivos Locais. IPEA, texto para discussão n.99, 2004.

SEBRAE/FADE - Serviço Brasileiro de Apoio às Micro e Pequenas Empresas. Estudo de Caracterização Econômica do Polo de Confecções do

Agreste Pernambucano. Relatório Final. FADE/ UFPE/ SEBRAE, Recife, maio de 2003. Disponível em: https://docs.google.com/file/d/0B_R9cylq9erzZ1U5d24wb0xGLTg/edit. Acesso em 15/04/2014.

SEBRAE/PE. Estudo econômico do arranjo produtivo local de confecções do Agreste pernambucano, 2013. Disponível em:

http://www.sebrae.com.br/uf/pernambuco/downloads/estudos-epesquisas/copy2 of aprenda/estudo-economico-do-apl-de-confeccoes-do-agreste.pdf. Acesso em 15/04/2014.

SEETHAMRAJU, R. Business process management: a missing link in business education. Business Process Management Journal, v 18, n. 3, p. 532-547, 2012. DOI http://dx.doi.org/10.1108/14637151211232696

SLACK, N.; CHAMBERS, S.; JOHNSTON, R.; BETTS, A. Gerenciamento de operações e de processos: princípios e práticas de impacto estratégico. Porto Alegre: Bookman, 2008. $532 \mathrm{p}$.

TAN, K. C. A framework $f$ supply chain management literature. European Journal of Purchasing and Supply Management, v.7, p.39-48, 2001.

ZANONI, G.; LIMA, E. P.; MATTIODA, R.; COSTA, S. E. G da. Modelo para Avaliação de Níveis de Maturidade na Relação Comprador-Fornecedor: um estudo de fornecedores da indústria automobilística, Revista Produção Online, Florianópolis, SC, v.13, n. 2, p. 703736, abr./jun. 2013. DOI: http://dx.doi.org/10.14488/1676-1901.v13i2.1334 Disponível em: < http://www.producaoonline.org.br/rpo/article/view/1334>. Acesso em 03 nov. 2014.

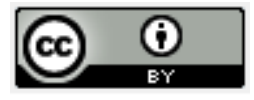

Artigo recebido em 05/12/2014 e aceito para publicação em 11/12/2014

DOI: http://dx.doi.org/ 10.14488/1676-1901.v15i2.1935 